Psychology and Sexuality (Preaching to the Choir Special Issue)

(https://cpasogii.com/special-issue)

All Flowers Bloom Differently: An Interpretative Phenomenological Analysis of the

Experiences of Adult Transgender Women

Elodie Eisenberg $\S^{1}$, Karyofyllis Zervoulis, Ph.D. ${ }^{2}$

${ }^{1}$ School of Health - Psychology, BPP University, United Kingdom

${ }^{2}$ School of Social Sciences - Psychology, London Metropolitan University, United Kingdom

$\S$ Address for correspondence:

Karyofyllis Zervoulis (c/o Elodie Eisenberg)

School of Social Sciences - Psychology (room TM1-63)

London Metropolitan University,

166-220 Holloway Road,

London N7 8DB

United Kingdom

Email: eisenbergelodie@gmail.com 
Elodie Eisenberg is a counselling psychology trainee at City University who completed her undergraduate studies at Warwick University before undertaking an MSc in Psychology at BPP University and is a graduate member of the British Psychological Society. In 2015, she became a consultant for an international NGO supporting victims of sexual and gender-based violence. From 2017 to 2018 she was employed by the NHS, in their forensic services, working closely with patients around gender issues and self-harm. Her research interests are i) psychology of sexual identity and gender roles ii) eating disorders and gender iii) pathophysiology of eating disorders

Dr Karyofyllis (Lakis) Zervoulis is a Social Psychologist with a PhD from University of Surrey, and he is a Chartered Member of the British Psychological Society. He is currently a senior lecturer in social psychology at London Metropolitan University. He has been, until recently, a psychology lecturer at BPP University since the development of the Psychology Department in 2012; in 2016, he became the Programme Leader of the BPP BSc (Hons) Psychology and the MSc Psychology [Conversion] programmes. He lectures mainly in Social Psychology as well as in Research Methods, Statistics and Data Analysis modules in Psychology. His main research interests are on i) social identity and politicisation as applied in the context of stigmatised and minority groups, ii) sexuality and gender roles, iii) internet psychology, and iv) cross-cultural psychology. Lakis previously held research positions at a number of UK Universities including Imperial College, Cambridge University, and University College London. 


\begin{abstract}
Many psychological studies focus on trans identity development in young individuals and on the stressors they often face, including the risk of chronic rejection or stigma internalization, but leave out the particularities of transitioning as an adult, particularly as a transwoman (TW). This study remedies this gap by conducting qualitative interviews on a sample of six transgender women above the age of 35, living in the United Kingdom, analyzed using interpretative phenomenological analysis (IPA). While transgender research typically shows that young individuals under the age of thirty go through a period of dissonance, followed by exploration and finally transition, adults may find that they experience a rather different sequence of self-discovery (Fraser, 2009). The current research found that older transwomen generally grow up feeling different, but that their lack of exposure to other trans individuals prevented them from voicing their identity until later life. The anticipation of negative reactions delayed their decision to transition and may have led them to reluctantly marry, have children and engage in over compensatory behavior in an effort to conceal their identity. The participants began openly exploring their identity with the spread of trans information on the internet, during which they sought new relationships that could bolster their need for coherence, often leading them to neglect individuals and environments that may have be nonverifying for some time. After a short period of open exploration, the respondents came out to the majority of their ecosystem, forcing them to redefine their relationships and their place in society. Physically transitioning appeared to improve most of the participants' mental wellbeing, helped them find a sense of authenticity and coherence, although this was generally mitigated by the consistency of support offered by family and friends.
\end{abstract}

Keywords: Identity; Gender; Trans Issues; Belonging; Coherence; Stigma 


\section{Introduction}

Until recently, it has been the practice in Western literature to depict gender as part of a static and binary system of categorization which allocates specific roles and significance to individuals (Kanter, 1993). At a more "institutional level", gender was viewed as a determinant of “individuals' roles, statuses, rights, and responsibilities" (Gagné \& Tewksbury, 1998) and cross-gendered behaviour was condemned as "deviant" (Schur, 1984). Recently, an enlightened body of research has replaced this consensus and has begun to more accurately represent the experiences of transgender persons. Nevertheless, much of the literature still qualifies their identities as disordered and reduces their experiences to living in the "wrong body". This inadequate definition fails to capture the many individuals who fall outside the "conventional" (Ellis, Bailey, \& McNeill, 2015) and "culturally-bound" (Barr, Budge, \& Adelson, 2016) binary understanding of gender, including transwomen, transmen and anyone with other labels such as bigender and gender queer (or non-binary). In fact, for some transgender individuals, living in their gender identity may not involve physical changes (Dargie, Pukall, Lyndsay Blair, \& Coyle, 2014), while others who do undergo either or both hormone therapy and sex reassignment surgery may continue to place themselves on a variable gender spectrum that is not limited to a binary model. The diversity of terminology used to describe these individuals symbolises the complexity and fluidity of gender identity and prohibits us from using a catch all, psychopathological lens. Subtle variations in experiences between different transgender groups must therefore be noted. Stieglitz (2004) concluded that the differences between female to males (FTM) and male to females (MTF) are often ignored even though the particular challenges each group may face vary considerably. Transgender women, in comparison to transgender men, for example, tend to suffer more from psychosocial factors such as "depressive symptoms, discrimination, and financial hardship" (Gamarel, Reisner, Leaurenceau, \& Nemoto, 2014). These elements are linked to a high prevalence of 
unprotected sex among transwomen, and therefore to a greater risk of negative health outcomes such as human immunodeficiency virus (HIV) and other sexually transmitted infections (STIs) (Brennan et al., 2012; Institute of Medicine, 2011). According to Timothy Cavanaugh, other long term issues may arise from the decline of the effectiveness of hormone therapy with age. Differences may also appear within groups. Identity in older male to female (MTF) adults appears to be more complex, multifaceted and often develops at a slower pace than the identities of younger MTF individuals (Grossman, 2006). Older transwomen may struggle to develop positive identities due to spending half of their life hiding their gender identity, complex relationships after coming out with their ex-partners, children and friends. As a result, their transition may require more social and emotional support because families and close friends, usually providers of social support, often become the cause of stress (Brown, 2008; Budge, 2012).

\section{Identity Development}

Theories around identity development may provide a valuable background against which older transwomen's experiences may be analysed. Identity development is based on the balance between authenticity, external demands and the desire to belong.

While most individuals internalize gender norms in a visible way, transgender identities develop undetected by society and therefore do not mirror the person's actual and authentic self (Bockting \& Coleman, 2007). According to Levitt and Ippolitos (2014), gender identity is formed through an interplay between a desire for authenticity and external demands. Internal gender experiences are combined with external assessments to create a coherent identity. Gender is regarded as a product of social interactions and personal experiences rather than being based on biological factors. 
"Self-verification", on the other hand, also seems to be one of the most basic human needs (Swann, 1990). Indeed, the desire to be seen by others in a way that is consistent with one's established self-view suggests a "fundamental need for psychological regularity and coherence" (Bosson, Taylor, \& Prewitt-Freilino; Lecky, 1945; Swann, Rentfrow, \& Guinn, 2003) and may be more important than a simple positive evaluation. The ability to express one's gender identity regardless of context contributes to the feeling that a person is recognized and appreciated by others (Swann, 1990) and may become a more prevalent need around midlife. Life course theory points to an escalating awareness of death around middle age (Nemiroff \& Colarusso, 1985) that may lead individuals to reject or correct earlier identification with social groups, and favour more authentic views of the self that are not dictated by "inner conflicts and external demands" (Levinson, 1986) and allow for the construction of a coherent life narrative (Kertzner, 2001).

Nevertheless, these fundamental needs may collide with the innate desire to belong. According to Maslow (1968), "love and belongingness" form part of the basic needs of life, whilst the formation and maintenance of relationships is essential to positive development (Bowlby, 1969). Similarly Richman and Leary (2009) suggest that "human behaviour, emotion, and thought are pervasively influenced by a fundamental interpersonal motive to obtain acceptance and to avoid rejection by other people". Gender non-conformity, especially male to female identity, has been linked to pervasive psychological and physical gender abuse from schoolmates, colleagues, mental health professionals and family members (Lombardi, Wilchins, Priesing, \& Malouf, 2001). Indeed, rates of discrimination among TGNC individuals still reach $60 \%$ (Rood et al., 2016). This abuse may therefore lead these individuals to conceal their identity in an effort to belong and avoid rejection. According to the minority stress model (Meyer, 1995), distal stressors such as rejection, prejudice and discrimination lead individuals to develop proximal stress processes that translate as internal mechanisms such as the 
concealment of identity, internalized stigmatization and the expectation of rejection (Rood et al., 2016). An analysis of the transgender literature reveals a high prevalence for mental health problems and lower well-being among trans individuals (McCann \& Sharek, 2016; Dargie, Pukall, Lyndsay Blair \& Coyle, 2014), and worryingly high rates of suicides and attempted suicides (Wylie \& Wylie, 2016; (D'Augelli, 2007). Nevertheless, it is the marginalisation and stress suffered by trans individuals due to their minority status that makes them more predisposed to mental health difficulties rather than being transgender itself (Dargie, Pukall, Lyndsay Blair, \& Coyle, 2014; Weyers et al., 2009). Indeed, having a stigmatised identity may trigger a host of stressors and psychological difficulties that trans individuals may try to emotionally regulate (Hatzenbuehler, Nolen-Hoeksema, \& Dovidio, 2009) through rumination (Nolen-Hoeksema \& Morrow, 1993), the suppression of an emotionally expressive behaviour by fear of a "backlash" (Spencer, 2003) or by seeking social support (Branscombe \& Ellemers, 1998). Both rumination and suppression may have a further amplificatory impact on psychological and emotional distress. The pursuit of social support, on the other hand, may have a positive effect on the emotional modulation of those with concealable stigmas, although they may struggle to find sources of social support (Hatzenbuehler, Nolen-Hoeksema, \& Dovidio, 2009). It is important, however, to note that overgeneralizing an assumption that psychopathology is prevalent among all gender nonconforming individuals may in itself become a form of prejudice and discrimination, and might lead to furthering the internalization of stigma (Nadal, Skolnik, \& Wong, 2012).

\section{Social Isolation}

Social isolation appears to be more prevalent among trans individuals more generally. Many studies suggest that transgender individuals feel "alienated from mainstream society" (Barr, Budge, \& Adelson, 2016), and find the lesbian, gay, bisexual and transgender (LGBT) 
community to be their only source of support (Bockting, Benner, \& Coleman, 2009; Singh, Hays, \& Watson, 2011). Indeed, while romantic relationships tend to be a genuine source of social support that may not be replicated by other types of relationships (Feeney \& Collins, 2014), a study by Blair and Hoskin (2018) uncovered that there still exists a severe bias toward excluding trans individuals from the dating pool, especially transwomen. When trans individuals were considered, transmen seemed to be favoured over transwomen regardless of the person's sexual and gender identity. The lack of inclusion of transwomen in the dating pool suggests that transwomen may generally benefit less from a crucial source of social support, face stressors such as when and how to come out to those they date (Iantaffi \& Bockting, 2011), anxiety about their possible partner's response to their reveal and their subsequent discrimination (Riggs, von Doussa, \& Power, 2015).

Nevertheless, LGBT networks also appear to have a positive effect on transitioning adults and the mental health of transgender persons (Graham, 2014; Nardi, 1999). This can be explained by the comfort associated with finding individuals whose identities also fall "outside the norm" and may therefore render stigmatization less challenging (Jones et al., 1984). Indeed, coherent and reliable social support may act as a buffer against the nocuous effect of minority stress on psychological well-being (Wong, Schrager, Holloway, Meyer, \& Kipke, 2014) while being ignored or rejected by parents, relatives, friends, and the larger society rather than validated and supported, may lead individuals to internalize "stigmatization messages" (Otis et al., 2006). Transgender persons who are surrounded by family and close friends during their transition have a better self-image, higher self-esteem and stronger resilience compared to individuals who do not (Golub, 2010; Nardi, 1992). Moreover, family and social networks who reject the trans individual render them more vulnerable to abuse, discrimination and mental health problems (Graham, 2014). 


\section{Current Study}

Despite increased research interest in this field, less than $30 \%$ of mental healthcare workers are familiar with the issues that affect transgender and gender non-conforming (TGNC) individuals (APA, 2006), which leads to insufficient levels of care (Ellis, Bailey, \& McNeill, 2015). Numerous studies on transgender people have focused on the identity development of young individuals and the stressors they may face coming to terms with their trans identity (Institute of Medicine, 2011), whilst leaving out the particularities of transitioning as an adult. This study therefore aims at providing a clear picture of the complexities of trans identities by focusing on the experiences of older transwomen who have undertaken medical procedures allowing them to live in their gender identity. The researchers chose a qualitative approach to give as personal an account of the lived experiences of six adult transgender women who are now living in their gender identity and are all at different stages of their transition. All the participants grew up in England between the 1960s and 1980s, a period during which being transgender was still highly uncommon. Despite substantial research in the field during this period, such as Harry Benjamin's textbook, The Transsexual Phenomenon (1966), gender reassignment remained highly stigmatised both socially and medically. It wasn't until the ratification of the Gender Recognition Act in 2004 that transgender people acquired legal recognition of their preferred gender and that their positive experiences became more mediatised.

Through its critical realist lens, it seeks to understand the participants' realities by combining interpretation with explanation and attempts to offer a more holistic understanding of older transwomen's experiences. The researchers believe in the fundamental importance of improving the standards of trans-affirmative practice (American Psychological Association, 2015) and of equipping healthcare and well-being professionals with a clearer understanding of the particular needs of older transgender women. While this research acknowledges that 
these individuals are now living in their gender identity, it does not see transition as a singular event, but rather as a journey and understands gender identity to be fluid rather than one dimensional.

\section{Method}

\section{Sample}

A purposive sample of six participants (Table 1), were recruited through LGBT organizations in the United Kingdom, as well as through social media between April 2017 and June 2017. Participants were recruited on the basis of three criteria; each participant should be living in their gender identity, they must identify as male to female and be above 35 years of age.

Table 1

Participants' details

$\begin{array}{ll}\text { Pseudonym } & \begin{array}{l}\text { Gender Assigned Gender Identity Age Age of Transition } \\ \text { at Birth }\end{array}\end{array}$

\begin{tabular}{lllll}
\hline Sandy & Male & Female & 52 & 50 \\
Amber & Male & Female & 37 & 34 \\
Jenny & Male & Female & 52 & 49 \\
Chloe & Male & Female & 54 & 51 \\
Josephine & Male & Female & 47 & 46 \\
Lisa & Male & Female & 36 & 35 \\
\hline
\end{tabular}

\section{Interviews}

The interviews were conducted at the BPP Waterloo Campus in London and over Skype and were recorded through a recording software on the researchers' computer. The interviews 
lasted between one to two hours. The audio files were stored on a password protected file, anonymized, and transcribed verbatim.

The interview began by asking the contributor one lead question, which is consistent with IPA: “can you start by telling me about your experience with transitioning?". This open question was chosen to gather background information about the participant, such as when they came out, their martial and familial status and possibly the stage of their physical transition. The answer to this question would typically dictate the direction of the rest of the interview and the questions asked subsequently were contingent on which elements were stressed by the participant in this introductory question.

Despite the relatively structured nature of the questions, the interview was led in great part by the participant. This allowed the researchers to delve deeper into some topics, allowed for a more natural identification of patterns and ensured 'accuracy in interpretation' (Galletta, 2013, p. 78).

\section{Data Analysis}

Given the lack of research about the experiences of older transwomen, this study opted to use the principles of interpretative phenomenological analysis in order to enter both the social and psychological world of the participant. Its qualitative and polyvocal nature, more generally, allowed the researchers to create a narrative that recognised the existence of a plurality of realities that may each be influenced by both cultural and social structures as well as by the interviewees' inner thoughts and feelings. The semi-structured interview therefore allowed the researchers to delve as deeply as possible into the respondents' worlds.

The data were analysed in line with IPA principles, through a double hermeneutic lens (Giddens, 1984) - by trying to make sense of the participants' attempts at making sense of their own experiences. The researchers first engaged analytically with each individual transcript to 
understand the idiographic experiences of the participants, while considering their role as researchers in their interpretation. Indeed, through its critical realist lens, the study acknowledges that no independent truth can really exist but rather that the results of the data analysis are a product of the author's interpretation. The researchers first used the technique of "bracketing" (Husserl, 1999) in their first reading of the text and made notes of their thoughts in margins while recording any emerging interpretations in a separate diary. Preliminary themes were subsequently identified, relationships between them were established and grouped together into clusters to form superordinate themes (Table 2) (Pietkiewicz \& Smith, 2012). At this stage, psychological concepts and language were used to apply IPA analysis (Willig, 2001). The construction of themes in a chronological order reflected the need to demonstrate the common sequential nature of transitioning as a an adult transwoman.

\section{Results}

Table 2

Themes

\section{SUPERORDINATE Selected Illustrative Quotes THEMES}
Feeling different "In myself, I knew from a very early age, and I would probably say six, seven, I knew I was different” (Sandy, 52)

Repression

"I was attempting to perform masculinity because that's what I thought I was supposed to do" (Lisa, 36)

Exploration

"I liked the feel, and the, (erm)... just the way the clothes felt on me" (Josephine, 47)

Coming out and “(Transitioning) it's made me invisible really” (Amber, 37)

Transitioning

Authenticity

"I'm seeing the person I am when I look in the mirror" (Jenny, 52) 
Five main themes, representing the broad stages of the participants' transition, appeared throughout their narratives: feeling different, conforming, exploration, coming out and transitioning, authenticity.

\section{Feeling Different}

All of the participants shared that they began sensing that they were "different" at an early age. They could not formulate exactly why they were different, in part because of lacking exposure to trans information, which impeded them from ascribing meaning to their feelings. While the participants could not fully comprehend this feeling of difference, they instinctively characterised it early on in negative terms:

"You get an innate sense, you may not be able to say what the fault is, but you know there is a fault" (Sandy, 52)

For many of the participants, school provided one of the first experiences of rejection and the subsequent internalization of rejection. They explained that while their peers could not identify what it was, they "intuitively" sensed a difference (Sandy, 52) and were often ostracized. Josephine, for example, recalled finding it difficult to "fit in" to a primarily male environment, particularly with "mainstream males". She perceived that they "never really liked" her, even though she could never understand why that was.

"I do think that you send out a-a sort of subliminal message to people? (erm) (...) So I did tend to get bullied quite a lot. And I could never really understand why? (erm)" (Josephine, 47) 
The participants also saw their identities develop at a time in which transgender issues were relatively unknown and the internet was not widely available. All of the participants explained that they did not have the vocabulary necessary to vocalise their feelings. This lack of information as well as being exposed to an often "unfriendly environment" contributed to increased feelings of isolation and led to an inability to socialise with people in a genuine manner:

"And so we can like try to cross that chasm, but you can't be a genuine intimate friend" (Amber, 37).

"in my childhood years and teenage years, I felt very confused because I didn't know who I was, and I felt like I was supposed to act in a certain way, but I didn't. It didn't feel right (...) I spent a lot of time feeling very anxious, feeling very kind of discordant." (Lisa, 36)

These feelings were compounded by internalised fears of losing family, friends or even employment:

"as a trans person you grow up believing that the world is against you and the society is going to ridicule you and laugh at you, nobody's going to give you a job, you have no credibility and be violent." (Jenny, 52)

Lack of information around trans issues and exposure to other individuals who felt similarly also led all of the participants to internalize wrong ideas about being transgender: 
"until 2010 (...) my only exposure to transgender people was-was through porn. So you sort of think to yourself, “Well, that's all you can do, is be a porn star or a hooker." [laughs]" (Josephine, 47)

\section{Conforming}

All of the participants grew up between the 1960s and 1980s, a time in which most societies fully subscribed to a binary gender paradigm with specific gender roles assigned to both men and women. The internalisation of social expectations therefore influenced their decision to repress their nascent feelings:

...you just put up and shut up. If you were uncomfortable in the male dressing room, you just had to get over it... (Sandy, 52)

Peer acceptance and the avoidance of rejection was one of the first catalysers of conformity for the majority of the participants. Indeed, some of the participants strategically modified their behaviours and internalized socially constructed gender norms in order to "fit in". Sandy, for example, utilized the term "put up" to stress her considerable lack of choice in the matter. She explained that her goal was "peer acceptance" and therefore conforming was a means to avoid rejection.

Most of the participants explained that they followed what can be considered conventional paths by getting married, having children and choosing male dominated industries. Chloe and Amber, in particular, described their lives prior to transitioning in a mechanical way and appeared not to have questioned their choice: 
“...these things that a lot of transgender people do, which is, you know, trying to ignore it, trying to find a way to get married, have children and all these sorts of thing...” (Chloe, 54)

Similarly, Amber explained that she had learnt to cultivate a distinct male identity:

$$
\begin{aligned}
& \text { "I think it (boarding school) was a fairly good opportunity to help me } \\
& \text { fit in. You know, like I learnt a lot of the skills that helped me live as } \\
& \text { a man." (Amber, 37) }
\end{aligned}
$$

For four of the participants, repressing their desire to identify with being transgender, created a great sense of confusion, which could have contributed to the deterioration of their mental wellbeing. It may have helped contribute to the onset of episodes of depression and anxiety and may have catalysed three of the respondents' suicidal ideations:

“...when I was feeling the lowest, it was because I felt like

a kind of emptiness, but also a complete confusion about who I was. And up until last year, I think, I never had an experience of identity, like, I didn't know what identity meant..." (Lisa, 36)

In an effort to "fit in", some of the participants also engaged in over compensatory behaviours such as growing beards, buying stereotypically male items or simply by being “overly male”: 
Experiences of Adult Transgender Women

"I was bigger than am I now. I had a beard. I was-like I was just mister testosterone really" (Amber, 37)

Josephine, on the other hand recounted that her confused sense of self was aggressively externalized and her attempts at being assertive were reflected by a stereotypical understanding of being a male:

"I think a big part of it was (erm) overcompensating. So I've never really been able to balance being assertive and being a bully. So when I thought I was being assertive, people would respond to it as I was being a bully" (Josephine, 47)

"I guess, a lot of people struggle because I am so different. I was quite a blocky bloke at certain times. They look at me, and say we don't understand - who was the old Jenny?" (Jenny, 52)

\section{Exploration}

Throughout the participants' narratives, exploration seems to have appeared sporadically throughout their lives before coming out and transitioning.

Most of the participants began exploring their feelings early on in life by trying on their mothers' clothes for example:

"it was around about 12 years old I just suddenly found myself drawn to my parents' room and go to my mother's wardrobe (...) I just couldn't help myself (...) and so I do that for a while, and then I would 
Experiences of Adult Transgender Women

feel guilt, and shame, and think, oh, no, this is totally wrong" (Chloe, 54).

While most of the participants stopped cross-dressing during early adulthood or after getting married, Chloe used it as an element in the bedroom as she explained to her wife that dressing as a woman aroused her. Her wife was nevertheless not accepting of her living fully as a woman, which kept Chloe from embracing her identity until after their divorce. Once she did come out, however, the sexual component faded away, and the nature of her identity was entirely redefined.

Most of the participants' decision to fully begin exploring their feelings prior to coming out, correlated with trans information being more readily available to them:

"I guess the Internet is the biggest history encyclopedia out there and once the research becomes available, um... you realize there are other people out there” (Jenny, 52).

Some of the participants found platforms where they could express their identity more openly. Amber, for example attended cross-dressing clubs, although she found that it was not the right place for her to express herself:

"Basically, I had been experimenting (...) I went to the club and like it was thrilling to be out (..) And then it all got a bit sexual (...) It's just not my thing. It's like just they aren't people like me and Ijust knew that those were the men that wore women's clothes for kick" (Amber, 37) 
This narrative highlights how her road to self-discovery was highly varied emotionally. Initially, meeting similar individuals was thrilling. She quickly realized, however, that the people she met were in a sense borrowing this identity while she struggled to acquire one. It was at this moment that she found a strong identity for herself. She felt like she was a woman permanently and not an occasional "cross-dresser".

Similarly for Josephine, cross-dressing never felt fulfilling as her appearance did not reflect how she deeply felt and what she imagined the clothes should make her feel like:

\begin{abstract}
"For me it's always been, I wanted to be a woman in woman's clothing. So when I-if I did dress up, I was always really disappointed that I still just looked like a boy in a-in girls' clothes." (Josephine, 47)
\end{abstract}

\title{
Coming out and Transitioning
}

The discovery that one is not alone, either through an exposure to trans issues on the internet or by coming into direct contact with individuals through organizations, helped confirm the participants' need for identity coherence. In Lisa's case, coming into contact with feminist organizations and women's sports during university proved a great influence. She explained in her interview that being surrounded by strong-willed women in a female-dominated community positively affected her understanding of gender. Discussions surrounding gender issues led her to reflect on her own identity and how engaging with this community came to impact her decision to transition.

Nevertheless, while LGBT organisations were an initial source of support for many of the participants, coming out meant involving their whole ecosystem. The validation of their identity by family and friends became of greater importance. Amber explained for example 
that transitioning socially was equally as important as the physical transition, as being recognised by those she loved or her community was enough to mirror her identity:

"And but [ah] as the process went on, what I found actually was that social transition cured almost the vast majority of my dysphoria physically speaking." (Amber, 37)

In order to ensure the stability of their family life, some of the women found they had to compromise on their identity. Jenny explained for example that she lives publicly as a woman most of the time while still living privately in her gender assigned at birth in front of her children as a way to maintain her identity as their "father". She expounded that when an individual comes out, their whole ecosystem is involved and couples may have to renegotiate their dynamic while their partner may have to reconsider their own identity:

"She is kind of struck and she still doesn't fully understand herself who she is and what she is, and how she identifies in that way, and it's, I guess, it's the biggest issue she has is" (Jenny, 47)

Similarly, Josephine explained how she had to renegotiate her intimate relationships and adopt a new role after transitioning:

"You know whereas now, we're, you know just two women sharing a home (...) and I'm sort of more of the, the sort of aunty if you like”. (Josephine, 47) 
For others, coming out might mean severing ties with the whole family as was the case for Chloe, whose children ceased most contact with her three years prior to this interview. She also detailed how she often feels isolated in her workplace:

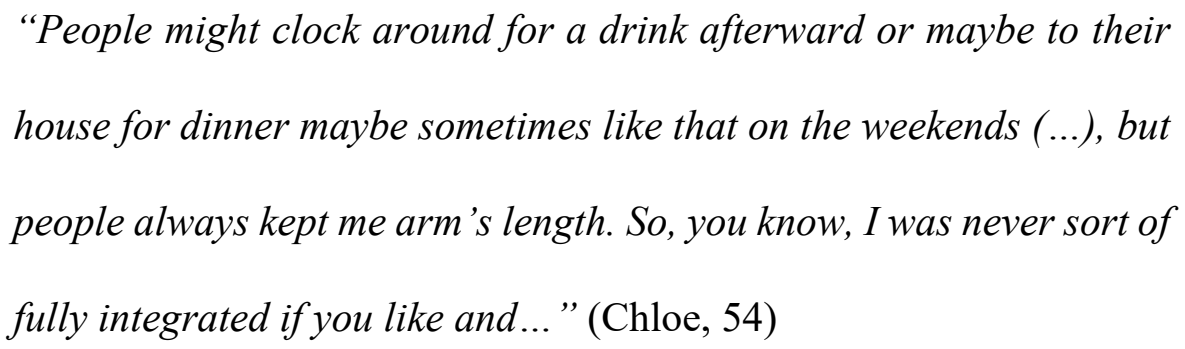

The degree to which each participant felt the need to "pass" varied considerably. For some, social transition was sufficient, while for Chloe it was essential to be recognized externally solely as a woman and not as a transwoman:

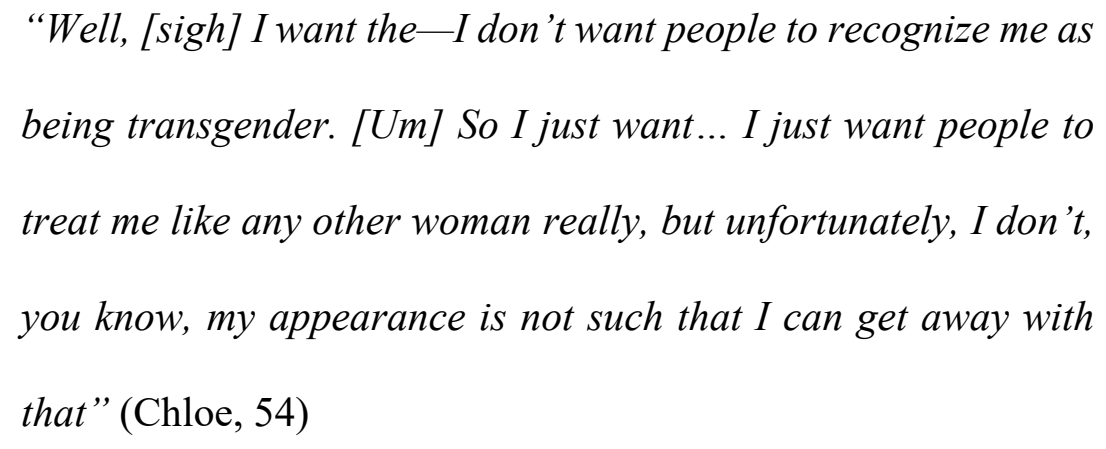

Conversely, for the other women, being in their preferred gender enough to allow them to feel more comfortable and integrated in society:

"I can walk in the street now-I can see a pair of eyes hit me, and they slide off me in disinterest now (...) it's made me invisible really which is lovely (...) you know I can participate in sort of work and society without being sticking out like sore thumb really” (Amber, 
Physically transitioning also allowed three of the participants to rediscover their sexuality. They found that it had become more fluid and that sexual pleasure was experienced in a whole new way. Lisa discovered that transitioning meant that she could have intercourse without feeling violated, while Amber had to explore a whole new identity in the bedroom. She explained that for 25 years she was aroused by the fantasy of being a woman, but that after transitioning, this idea could no longer be a source of arousal:

"Well, no. I didn't like sex. So I didn't-one of the things was I
hated. I really strongly didn't like penetrating women (...) it's
kind of trying to discover and learn what turns me on now" (Amber, 37)

Conversely to the other participants who fully transitioned, Jenny felt that her "body dysphoria" did not extend to her sexual organs. Instead, she insisted on the fact that her identity was something that she felt so strongly internally that she did not need it to be reflected through her sex organs. Indeed, one aspect of compromising for her family was to often present as a man at home as well as in the bedroom.

\section{Authenticity}

For all of the participants, coming out and transitioning was a way to reconcile their internal identity and their external image, live authentic lives and form genuine relationships.

Most of the participants found that after experimenting they could entirely reconcile their appearance with the way they intuitively felt, although the extent of the physical transformation for each woman varied. Jenny undertook extensive laser hair removal, lost weight and bought 
a new wig. These elements of change were sufficient for her to redefine herself and reconcile her internal and external identity:

“...I-I felt better about myself physically, and mentally, and visually. I'm seeing the person I am when I look in the mirror. I actually believed that was me..." (Jenny, 52)

Similarly, Josephine expounded that although she may appear different to others, her external image simply is reflective enough of her true self and allows her to feel more "settled":

“... now, when I look in the mirror I see someone I recognize.

(erm) And I think through that the way I interact with the world is different. "(Josephine, 47)

Throughout participants' narratives, it became clear that the resolution of identity confusion came with a newfound authenticity and an ability to form genuine relationships. Amber finally entered relationships in which she could truly be herself:

...pretending to be a big spender or whether you know, you are pretending to be happy in your marriage and you are not, just maintaining that façade is like really high energy thing, and I don't have to do that anymore. I am just sort of out, and able to live an authentic life (Amber, 37)

Jenny, on the other hand, described an all-male organization's dinner party she attended as a female speaker, after presenting as a man for many years. It signified hope for a future where she could be seen the way she feels inside, while being accepted as female in a "man's world" appeared to hold great value for her: 
“...And they said well, as you are a past national president, we would really like you there. And I said, well, I'd love to be there. But this is who you are going to get (...) So I was the only female in a-in a celebration day in which there was about 4,000 men" (Jenny, 52)

While most of the participants found that people engaged more with them, Chloe particularly felt that being "visibly" transgender alienated her more. This idea correlated with the aforementioned feeling of being dissatisfied with her transition and not being able to "pass" as a woman, accentuating this persistent sense of difference:

"I love dancing and I... I just love going there and just be like anyone else. But I get this quite a bit ... women maybe in sort of early 20 s is that they look at me and see that I am trans, but rather than just treat me like any other woman and move like you just ignore me, you know, [um] quite often they will come over and say, 'well, I-we-I think what we think you look like a transgender. Can I take a selfie with you on my phone?"', (Chloe, 54)

Instead of being seen as a woman, Chloe felt that her identity after transitioning made her more visible in a way that she did not desire. Her choice of words particularly emphasized the caricaturized way she feels people treat her, increasing this pre-existing feeling of difference and isolation.

Most of the participants felt that while they were transitioning physically, there were also many adjustments required socially. They discovered that their identities are both fluid and multifaceted. Lisa's narrative encapsulates perfectly the complex and multifaceted nature of her gender identity: 
"I think there's multiple levels of it. There are things, like, the fact that I know, I know I'm a woman. That's very obvious. That's very clear to me and that's the first feeling that I've ever had about, like, personal identity. When I say that I identify as trans, that's quite a... It's a political identity and it's the fact that, like, it really bugs me when people say what gender do you identify as? Because, like, it's not about me identifying as a woman. I am a woman." (Lisa, 36)

Comparably, Amber explained that being a woman wasn't something that she could just be, but rather an identity that she truly acquired as she was socialised as a woman:

So of course I'm a trans-woman and I'm also a woman and those two things are not incompatible and (...) I'm a woman is like-you know it's actually more complex than that and there's plenty of days when I wake up and I don't feel it (...) I think I actually grew into being a woman (...) living as a woman it will teach you, what being a woman is about" (Amber, 37)

Josephine, on the other hand, expounded that coming out for transwomen is beset with conflicting issues, especially with regards to the complexity of renegotiating an identity. She was able to find her place and be seen for her true self, while also learning how to deal with the challenges that come with this new identity:

"it sort of cuts both ways, but being a woman in the workplace you-they don't take you quite as seriously, and I'm starting to find that a lot, you know, with being cut off and talked over and not asked for my opinion" (Josephine, 47) 
Finally, most of the women expressed that as they grew into their identity they became more resilient and confident. While their previously internalized fears about being rejected faded away, they were better able to defend their identity:

\author{
"I built resilience and I built self-confidence, and also \\ pride, and I feel like, the way that I present myself, I am \\ generally proud of, and if somebody attacks, like, it's \\ not ok." (Lisa, 36)
}

\title{
Discussion
}

The aim of the current study was to explore the experiences of transwomen who came out after the age of 35 in the United Kingdom, to improve the standards of trans-affirmative care. After a careful analysis of the above results, the researchers found a similar pattern throughout the participants' narratives.

All of the respondents expressed feeling different from an early age and often being isolated or unable to engage in genuine relationships. The participants expounded that as they started understanding this difference they also began fearing the consequences of their secret being exposed. This led them to expect rejection and therefore internalized and concealed their stigma (Hendricks \& Testa, 2012). Most of the respondents described a subsequent period of confusion and anxiety, some misused alcohol, while three attempted suicide as a result of fearing rejection and conforming (Dargie, Pukall, Lyndsay Blair, \& Coyle, 2014; Weyers et al., 2009). The participants engaged in overcompensating, hypermasculine behaviour prior to coming out in an effort to "fit in". These results confirm prior research indicating that identity development is based on the balance between external demands, the desire to belong (Maslow, 1968) and authenticity. Indeed, by choosing not to identify as transgender, the participants reflected the idea propounded by Richman and Leary (2009), that people's behaviour, thoughts 
and emotions are modulated by external demands and driven by the desire to be accepted by others. Nevertheless, this conflict appeared to be resolved after the age of 35 for the participants who felt that they favoured a more authentic view of themselves as they grew older (Levinson, 1986) and sought new relationships that could bolster their need for coherence (Levinson, 1986), often leading them to neglect individuals and environments that may have be nonverifying for some time (Swann \& Pelham, 2002). Indeed, due to having a concealable identity (Hatzenbuehler, Nolen-Hoeksema, \& Dovidio, 2009) they benefited more from seeking social support from individuals who shared the same stigma. They did so by using internet platforms, clubs or organizations. Coming out for these women coincided historically with the spread of the internet and the emergence of a wider and more visible community of trans individuals. This overlap emphasises the importance of community support, to nurture a sense of belonging and encourage the expression of an identity that is reflected back in a consistent and positive manner (Wong, Schrager, Holloway, Meyer, \& Kipke, 2014).

Aside from Chloe, who maintained a sense that her appearance does not fully reflect the way she internally feels, the other participants found that their gender identity was recognized by others and that it contributed significantly to feeling authentic (Bockting \& Coleman, 2007). This sense of coherence allowed them to create genuine relationships and improved their mental well-being considerably. These differing results may be explained in part by Chloe's felt social isolation and rejection by her family. Indeed, social support from family and friends may act as a buffer against the adverse effects of minority stress (Wong, Schrager, Holloway, Meyer, \& Kipke, 2014) while being rejected by loved ones may result in the internalisation of stigmatisation messages (Otis et al., 2006).

The participants also revealed that despite transitioning both physically and socially, their identity remained multifaceted and in constant flux (Grossman, 2006), and that they had to learn how to renegotiate their role both in society and among their loved ones. Sandy, 
Josephine and Jenny were all able to retain stable relationships with their wives by redefining their identity as a couple. Indeed, participants reported a great influence of their transition on their cisgender partner's own sexual identification (Brown, 2010) and subsequent social group membership (Pfeffer, 2014). Amber now lives with her supportive partner whom she met two years prior to her Interview.

The study used a qualitative design of a subjective nature. In spite of the consideration of reflexive issues, the analysis and conclusions drawn from this research might be tainted by the researchers' own understanding of trans issues. It offers a holistic yet limited picture of the pre-transition experiences of adult transwomen who try to make sense of events having taken place many years prior.

A further limitation stems from the semi-structured nature of the interviews, in that they differed greatly from each other, and though this tailored approach is consistent with the principles of IPA, the length of this article limits the amount of material that could be included. Although the individuals who participated in this study discussed their families, including expartners and children, certain nuances of relationships, attachments, conflicts and resolutions were impossible to fully capture.

Despite its small sample size, this research is of crucial importance as it tackles the challenges of aging trans women who are a unique and understudied population. This article provides a starting point from which subsequent research could draw upon. Longitudinal studies could perhaps explore the effects of transition on transwomen's experiences with employability, social status and reintegration into the work place. As was pointed out by two of the participants who had successful careers as men, re-entering the workplace as a woman triggered the need to renegotiate relationships and attitudes. A longitudinal study would allow 
for improved understanding of the ways they could cope with changing relationships, the renegotiation of their identity and adapting to their transition.

\section{Conclusions}

The present research established that the transwomen in this sample grew up feeling different, but that their lack of exposure to other trans individuals prevented them from identifying as such until later in life. The anticipation of negative reactions may have led them to engage in over compensatory behaviour such as getting married or taking on stereotypically male roles, in an effort to conform. The participants began openly exploring their identity with the spread of trans information on the internet, during which they sought new relationships with individuals who could mirror their identity and therefore reconcile their need for coherence with a greater sense of belonging. After a short period of open exploration, the respondents came out to the majority of their ecosystem, forcing them to redefine their relationships, their partners' roles and sexuality as well as their place in society and at work. Physically transitioning appeared to improve most of the participants' mental wellbeing, helped them find a sense of authenticity and coherence, although this was generally mitigated by the consistency of support offered by family and friends.

\section{References}

Archer, M., Bhaskar, R., Collier, A., Lawson, T., \& Norrie, A. (1998). Critical realism: essential readings. Abingdon: Routledge.

Adnoy Eriksen, K., Arman, M., Davidson, L., Sundfor, B., \& Karlsson, B. (2013). Challenges in relating to mental health professionals: Perspectives of persons with severe mental illness. International Journal of Mental Health Nursing, 23(2). 
APA, P. T.-B. (2006). Evidence-based practice in psychology. American Psychologist, 61, $271-285$.

Augustus, K., \& Golub, S. (2016). Family rejection as a predictor of suicide attempts and substance misuse among transgender and gender nonconforming adults. LGBT Health, 3(3), 193-199.

Baumeister, R. F., \& Leary, M. R. (1995). The need to belong: desire for interpersonal attachments as a fundamental human motivation. Psychological Bulletin, 117(3), 497529.

Badgett, M. V. I. (2003). Money, myths, money, myths, and change: The economic lives of lesbians and gay men. and change: The economic lives of lesbians and gay men. Chicago, IL: University of Chicago Press.

Badgett, M. V. I, Lau, H., Scars, B., \& Ho, D. (2007). Bias in the workplace: Consistent evidence

of sexual orientation and gender discrimination. Los Angeles, CA: The Williams Institute.

Balsam, K. F., Molina, Y., Beadnell, B. et al. (2011). Measuring multiple minority stress: The LGBT people of color micro-aggression scale. Cultural Diversity and Ethnic Minority Psychology, 17. 163-174.

Barr, S. M., Budge, S. L., \& Adelson, J. L. (2016). Transgender Community Belongingness as a Mediator Between Strength of Transgender Identity and Well-Being. Journal of Counseling Psychology, 63(1), 87-97.

Baumle, A. K., \& Poston, D. I., Jr. (2011). The economic cost of being homosexual: A multilevel

analysis. Social Forces, 89, 1005-1031. 
Borrell, L., Diez Roux, A., Jacobs, D., Shea, S., Jackson, S., Shrager, S., \& Blumenthal, R. (2010). Perceived racial/ethnic discrimination, smoking and alcohol consumption in the Multi-Ethnic Study of Atherosclerosis (MESA). Preventive Medicine, 51(3-4), 307312.

Bosson, J. K., Taylor, J. N., \& Prewitt-Freilino, J. L. (2006). Gender Role Violations and Identity Misclassification: The Roles of Audience and Actor Variables. Sex Roles, $55(1-2)$.

Bouman, W. P., Claes, L., Brewin, N. et al. (2016). Transgender and anxiety: A comparative study between transgender people and the general population. International Journal of Transgenderism, 18(1).

Bowlby, J. (1969). Attachment and Loss. Volume I, Attachment. Basic Books.

Brown, D. (2008). African American resiliency: Examining racial socialization and social support as protective factors. Journal of Black Psychology, 34, 32-28.

Budge, S. L., Katz-Wise, S. L., \& Tebbe, E. N. (2012). Transgender emotional and coping processes. The Counselling Psychologist.

Budge, S., Tebbe, E. N., \& Howard, K. A. (2010). The Work Experiences of Transgender Individuals: Negotiating the Transition and Career Decision-Making Processes. Journal of Counseling Psychology.

processes: Facilitative and avoidant coping throughout gender transitioning. The Counselling Psychologist, 81, 545-557.

Clancy, M. (2013). Is reflexivity the key to minimising problems of interpretation in phenomenological research? Nurse Researcher, 20(6).

Clarke, V., \& Braun, V. (2013). Teaching thematic analysis: Overcoming challenges and developing strategies for effective learning. The Psychologist, 26(2), 120-123.

Cohen, L., \& Morrison, K. (2011). Research Methods in Education (7th ed.). Routledge. 
Cooley, C. (1902). Human Nature and the Social Order. Scribner.

Creswell, J. W. (1998). Qualitative inquiry and research design. Choosing among five traditions. London: Sage Publications.

Creswell, J. W. (2007). Qualitative Inquiry research Design: Choosing Among Five Approaches. Thousand Oaks, California: Sage Publications, Inc.

Currah, P, \& MOore, L. J. (2009). "We don't know who you are." Contesting sex designations in the New York City birth certificates. Hypatia, 24, 113-135.

Dargie, E., Pukall, C. F., Lyndsay Blair, K., \& Coyle , S. M. (2014). Somewhere under the rainbow: Exploring the identities and experiences of trans persons. Canadian Journal of Human Sexuality.

D’Augelli (1994). Identity development and sexual orientation: Toward a model of lesbian, gay, and bysexual development. In E. J. Trickett, R. J. Watts, \& D. Birmann (Eds.), Human diversity: Perspectives on people in context. San Francisco: Jossey-Bass.

D'Augelli, A. R. (2007). Transgender Youth and Life-Threatening Behaviors. Suicide and LifeThreatening Behaviour, 37(5).

Davey, A., Bouman, W. P., Arcelus, J., \& Meyer, C. (2014). Social support and psychological well-being in gender dysphoria: A comparison of patients with matched controls. International Society for Sexual Medicine, 11, 2976-2985.

Denny, D. (2004). Changing models of transsexualism. In U. Lell \& J. Drescher (Eds.), Transgender subjectives: A clinician's guide (pp 25-40). Binghamton, NY: Haworth.

Denzin, N. K. (1995). The Cinematic Society The Voyeur's Gaze. USA: SAGE Publications Ltd.

DiCicco-Bloom, B., \& Crabtree, B. F. (2006). The qualitative research interview. Medical Education , 40, 314-321.

Doorduin, T., van Berlo, W. (2013). Trans people's experience of sexuality in the Netherlands: 
a pilot study. Journal of Homosexuality, 61(5), 654-672.

Durkheim, E. (1897). On Suicide. Penguin Books Limited.

Eady, A., Dobinson, C., \& Ross, L. (2011). Bisexual people's experiences with mental health services: A qualitative investigation. Community Mental Health Journal, 47, 378-389.

Ellis, S., Bailey, L., \& McNeill, J. (2015). Trans people's experiences of mental health and gender identity services: A UK study. Journal of Gay \& Lesbian Mental Health, 19(1), $1-17$.

Fisher, A. F., Bandini, E., Casale, H., \& Maggi, M. (2013). Sociodemographic and Clinical Features of Gender Identity Disorder: An Italian Multicentric Evaluation. 10(2), 408419.

Flentje, A., Heck, N. C., \& Sorenson, J. L. (2014). Characteristics of transgender individuals entering substance abuse treatment. Addictive Behavior, 39, 969-975.

Fokkema, T., \& Kuyper, L (2009). The relation between social embeddedness and loneliness among older lesbian, gay, and bisexual adults in the Netherlands. Archives of Sexual Behavior, 38, 264-275.

Fraser, L. (2009). Depth psychotherapy with transgender people. Sexual and Relationship Therapy, 24(2), 126-142.

Fredriksen-Goldsen, K., Chengschi, S., Goldsen, J., \& Emlet, C. A. (2015). Successful aging among LGBT older adults: Physical and mentlal health-related quality of life by age group. The Gerontologist, 55(1), 154-168.

Fredriksen-Goldsen, K., Emlet, C.A., Kim, H. J. et al. (2013). Health disparities among lesbian, gay, and bisexual older adults: Results from a population-based study. American Journal of Public Health, 103(10), 1802-1809.

Frost, D. M., \& Meyer, I. J. (2009). Internalized homophobia and relationship quality among lesbians, gay men, and bisexuals. Journal of Counselling Psychology, 56, 97-109. 
Gagné, P., \& Tewksbury, R. (1998). Conformity Pressures and Gender Resistance Among Transgendered Individuals. Social Problems, 45(1).

Galletta, A. (2013). Mastering the Semi-Structured Interview and Beyond: From Research Design to Analysis and Publication. New York: New York University Press.

Galupo, M. P., Henise, S. B., \& Davis, K. S. (2014). Transgender microaggressions in the context of friendship: patterns of experience across friends' sexual orientation and gender identity. Psychology of Sexual Orientation and Gender Diversity, 1, 461-470.

Gamarel, K. E., Reisnder, S. L., Laurenceau, J. P. et al. (2014). Gender minority stress, mental health, and relationship quality: A dyadic investigation of transgender women and their cisgender male partners. Journal of Family Psychology, 28, 437-447.

Gamarel, K. E., Reisner, S. L., Parsons, J. T:, \& Golub, S. A. (2012). Association between socioeconomic position discrimination and psychological distress: Findings from a community-based sample of gay and bisexual men in New York City. American Journal of Public Health, 102, 2094-2101.

Goldblum, P., Testa, R. J., Pflum, S., Bradford, J., Hendricks, M. L., \& Bongar, B. (2012). The Relationship Between Gender-Based Victimization and Suicide Attempts in Transgender People. Professional Psychology: Research and Practice, 43(5), 468-475

Golub, S. A:, Walker, J. J., Longmire-Avital, B. et al. (2010). The role of religiosity, social support, and stress-related growth in protecting against HIV risk among transgender women. Journal of Health Psychology, 14, 35-44.

Graham, L. F., Halley, C. P., Tucco, J. et al. (2014). Interpersonal relationships and social support in transitioning naratives of black transgender women in Detroit. International Journal of Transgenderis, 15(2), 110-113.

Grossman, A. H:, \& D’Augelli, A. R: (2006b). Transgender youth: Invisible and vulnerable. Journal of Homosexuality, 51(1), 111-128. 
Grossman, A. H., D’Augelli, A. R., \& Salter, N. P. (2006). Male-to-female transgender youth: Gender expression milestones, gender atypicality, victimization, and parents' responses. Journal of GLBT Family Studies, 2, 71-92.

Hamilton, M. (1959). The assessment of anxiety states by rating. Journal of Medical Pscyhology, 32, 50-55.

Hare, I., Bernard, P., Sanchez F. J. Et al. (2009). Androgen receptor (AR) repeat length polymorphis associated with male-to-female transsexualism. Biological Psychiatry, 65, 93-96.

Heidegger, M. (1962). Being and Time. New York: State University of New York Press.

Hendricks, M., \& Testa, R. (2012). A Conceptual Framework for Clinical Work With Transgender and Gender Nonconforming Clients: An Adaptation of the Minority Stress Model. Professional Psychology: Research and Practice, 43(5), 460-467.

Henningsson, S., Westberg, L., Nilsson, S. et al (2005). Sex steroid-related genes and maleto-female transsexualism. Psychoneuroendocrinology, 30, 657-664.

Hepp, U., Kraemer, B., Schndyder , U., Miller, N., \& Delsignore, A. (2005). Psychiatric comorbidity in gender identity disorder. Journal of Psychosomatic Research, 58(3), 259-61.

Hirsch, J. (2006). A review of the literature on rural suicide: Risk and protectve factors, incidence, and prevention. The Journal of Crisis Intervention and Suicide Prevention, 27, 189-199.

Husserl, E. (1931). Ideas: General introduction to pure phenomenology. London: Allen and Unwin.

Institue of Medicine. (2011). The health of lesbian, gay, bisexual, and transgender people: Building a foundation for better understanding. The National Academies Press. 
Johnson, P. A. (2000). On Heidegger. Wadsworth Philosophers Series. Belmont: Wadsworth Thomas Learning.

Joiner, T. E. (2005). Why People Die By Suicide. Harvard University Press.

Kanter, R. M. (1993). Men and Women of the New Corporation. Basic Books.

Karp, D. (1996). Speaking of Sadness: Depression, Disconnection, and the Meanings of Illness. Oxford University Press.

Kessler, R. C., Berglund, P., Borges, G. et al. (2005). Trends in suicide ideation, plans, genstures, and attempts in the United States, 1900-1992 to 2001-2003. JAMA, 293, $2487-2495$.

King, S., \& Dabelko-Schoeny, H. (2009). "Quite frankly, I have doubts about remaining”:

Aging-in-place and health care access for rural midlife and older lesbian, gay, and bisexual individuals. Journal of LGBT Health Research, 5, 10-21.

Kraus, M. W., Chen, S., \& Keltner, D. (2011). The power to be me: Power elevates self-concept consistency and authenticity. Journal of Experimental Social Psychology, 47, 974-980.

Krefting , L. (1991). Rigor in Qualitative Research: The Assessment of Trustworthiness. The American Journal oj Occupational Therapy , 45(3).

Lee, M. G., \& Quam, J. K. (2013). Comparing supports for LGBT aging in rural versus urban areas. Journal of Gerontological Social Work, 56, 112-126.

Leighton, M. B. (2013). Trans Women and Aging: A Qualitative Study. Thesis, Master of Science In Family Studies.

Lev (2004). Transgender emergence: Therapeutic guidelines for working with gender variant people and their families. New York: Haworth Clinical Practice Press.

Levitt, H. M., \& Ippolito, M. R: (2014). Being transgender: The experience of transgender identity development. Journal of Homosexuality, 61(12), 1727-1758.

Loeb, L., \& Shane, M.(1982). The resolution of a transsexual wish in a five-year-old boy. 
Experiences of Adult Transgender Women

Journal of the American Psychoanalytic Association, 30, 419-434.

Lombardi, E. L., Wilchins, R. A., Priesing, D., \& Malouf, D. (2001). Gender violence: transgender experiences with violence and discrimination. Journal of Homosexuality, 42(1), 89-101.

Lyons, T., Shannon, K., Pierre , L., Small, W., Krüsi, A., \& Kerr, T. (2015). A qualitative study of

transgender individuals' experiences in residential addiction treatment settings: stigma and inclusivity. Substance Abuse Treatment, Prevention, and Policy, 10(17).

MacDonald, T., Noel-Weiss, J., West, D., Walks, M., Biener, M., Kiebe, A., \& Myler, E. (2016). Transmasculine individuals' experiences with lactation, chestfeeding, and gender identity: a qualitative study. BMC Pregnancy and Childbirth, 16(106).

MacKinnon, K. R., Tarasoff, L. A., \& Kia, H. (2016). Predisposing, reinforcing and enabling factors of trans-positive clinical behavior change: A summary of the literature. International Journal of Transgenderism, 17(2), 83-92.

Major, B., \& O'Brien, L. T. (2005). The Social Pscyhology of Stigma. Annual Review of Pscyhology, 56, 393-421.

Maslow, A. (1968). Toward a psychology of being. Van Nostrand.

McCann, E., \& Sharek, D. (2016). Mental Health Needs of People Who Identify as Transgender: A Review of the Literature. Archives of Psychiatric Nursing, 30(2), 280285.

McConnell-Henry, T., Chapman, Y., \& Francis, K. (2009). Unpacking Heideggerian Phenomenology. Southern Online Journal of Nursing Research, 9(1).

McGarity, L. A. (2014). Socioeconomic status as context for minority stress and health disparities among lesbian, gay, and bisexual individuals. Psychology of Sexual Orientation and Gender Diversity, 1(4), 383-397. 
McLemore, K. A. (2014). Experiences with Misgendering: Identity Misclassification of Transgender Spectrum Individuals. Self and Identity.

Meier, S. C., Sharp, C., Michonski, J. et al. (2013). Romantic relationships of female-to-male trans men: A descriptive study. International Journal of Transgenderism, 14, 75-85.

Melendez, R. M., \& Pinto, R. (2007). "It's a hard life”: Love, gender, and HIV risk among male-to-female transgender persons. Culture, Health \& Sexuality, 9, 233-245.

Meyer, I. H. (1995). Minority Stress and Mental Health in Gay Men. Journal of Health and Social Behavior, 36(1), 38-56.

Meyer, I. (2001). Why lesbian, gay, bisexual and trangender health?. American Journal of Public Health, 91(6), 856-859.

Miller, T., Birch, M., Mauthner, M., \& Jessop, J. (2012). Ethics in Qualitative Research. London:

Sage.

Millet, N., Longworth, J., \& Arcelus, J. (2017). Prevalence of anxiety symptoms and disorders in the transgender population: A systematic review of the literature. International Journal of Transgenderism, 18(1), 27-38.

Mollon, L. (2012). The forgotten minorities: Health disparities of the lesbian, gay, bisexual, and transgender communities. Journal of Health Care for the Poor and Underserved, $23,1-6$.

Morgan, S., \& Stevens, P. (2012). Transgender Identity Development as Represented by a Group of Transgendered Adults. Issues in Mental Health Nursing.

Morse, J. M. (1992). Qualitative health research. Newbury Park, CA: Sage Publications.

Moran, L., \& Sharpe, A. (2005). Violence, identity and policing: The case of violence against transgender people. Criminal Justice, 4(4), 395-417.

Motmans, J., Meier, P, Ponnet, K., \& T’Sjoen, G. (2011). Female and male transgender 
quality of life: Socioeconomic and medical differences. Journal of Sexual Medicine, 9, $743-750$.

Mustanski, B. S., Garofalo, R., \& Emerson, E. M. (2010). Mental health disorders, psychological distress, and suicidality in a diverse sample of lesbian, gay, bisexual, and transgender youths. American Journal of Public Health, 100(12), 2426-32.

Mustanski, B., \& Liu, R: T. (2013). A longitudinal study of predictors of suicide attempts among lesbian, gay, bisexual, and transgender youth. Archives of Sexual Behavior, 42, $437-448$.

Nadal, K., Skolnik, A., \& Wong, A. (2012). Interpersonal and systemic microaggressions toward transgender people: Implications for counseling. Journal of LGBT Issues in Counseling, 6, 55-82.

Nardi, P. M. (1992). That's what friends are for: Friends as family in the gay and lesbian community. In K. Plummer (Ed.), Modern homosexualities: Fragments of lesbian and gay experience (pp. 108-120). New York, NY: Routledge.

Nardi, P. M. (1999). Gay men's friendships: Invincible communities. Chicago, IL: Chicago University Press.

Nemoto, T., Boedeker, B., \& Iwamoto, M. (2011). Social support, exposure to violence and transphobia, and correlates to depression among male-to-female transgender women with a history of sex work. American Journal of Public Health, 101, 1980-1988.

Nuttbrock, L., Hwahng, S., Bockting, W. et al. (2010). Psychiatric impact of gender-related abuse across the life course of male-to-female transgender persons. Journal of Sex Research, 47, 12-23.

Nuttbrock, L., Rosenblum, A., \& Blumenstein, R. (2002). Transgender identity affirmation and mental health. International Journal of Transgenderism, 6. 
Orel, N. (2014). Investigating the Needs and Concerns of Lesbian, Gay, Bisexual, and Transgender Older Adults: The Use of Qualitative and Quantitative Methodology. Journal of Homosexuality, 61(1), 53-78.

Paz Galupo, M., Henise, S. B., \& Davis, K. S. (2014). Transgender microaggressions in the context of friendship: Patterns of experience across friends' sexual orientation and gender identity. Psychology of Sexual Orientation and Gender Identity, 1(4), 461-470.

Pietkiewicz, I., \& Smith, J. A. (2012). A practical guide to using Interpretative Phenomenological Analysis in qualitative research psychology. The Psychological Journal, 18(2), 361-369.

Picket, J. (2010). Addressing gay men's health - The script needs a rewrite. Virtual Mentor, $12,668-672$.

Pinto, R. M., Melendez, R., \& Spector, A. (2008). Male-to-female transgender individuals: Building social support and capital from within a gender-focused network. Journal of Gay and Lesbian Social Services, 20, 203-220.

Riggle, E. D. B., Rostosky, S. S., McCants, L. E., \& Pascale.Hague, D. (2011). The positive aspects of a transgender self-identification. Psychology and Sexuality, 2, 147-158.

Rogers, C. (1959). A theory of therapy, personality, and interpersonal relationships, as developed in the client-centered framework. In S. Koch, Psychology: A Study of a Science. Study 1, Volume 3: Formulations of the Person and the Social Context,. McGraw-Hill.

Rood, B. A., Reisner, S. L., Surace, F. I., Puckett, J. A., Maroney, M. R., \& Pantalone, D. W. (2016). Expecting Rejection: Understanding the Minority Stress Experiences of Transgender and Gender-Nonconforming Individuals. Transgender Health, 1(1).

Rotondi, N. K., Bauer, G. R., Travers, R. et al. (2011a). Depression in male-to-female 
transgender Ontarians: Results from trans PULSE project. Canadian Journal of Community Mental Health, 30(2), 113-133.

Rotondi, N. K., Bauer, G: R., Scanlon, L. et al. (2011b). Prevalence of and risk and protective factors for depression in female-to-make transgender Ontarians: Trans PULSE project. Canadian Journal of Community Mental Health, 30(2), 135-155.

Sanchez, F. J., Vilain, E. (2009). Collective self-esteem as a coping resource for male-to-f female transsexuals. Journal of Counselling Psychology, 56(1), 202-209.

Sandelowski, M. (1991). Telling Stories: Narrative Approaches in Qualitative Research. Journal of Nursing Scholarship, 23(3).

Savin-Williams, R. C. (1988). Theoretical perspectives accounting for adolescent homosexuality. Journal of Adolescent Health, 9(6), 95-104.

Savin.Williams, R. C. (1990). Gay and lesbian adolescents. Marriage and Family Review, 14, $197-216$.

Schmidt, C. K., Miles, J. R., \& Welsh, A. C. (2011). Perceived discrimination and social support: The influences on career development and college adjustment of LGBT students. Journal of Career Development, 38, 293-309.

Schur, E. M. (1984). Labeling women deviant: gender, stigma, and social control. McGrawHill.

Seidman, I. (2006). Interviewing As Qualitative Research. Teachers College Press.

Singh, A. A., \& McKleroy, V: S. (2011). "Just getting out of bed is a revolutionary act". The resilience of transgender people of color who have survived traumatic life events. Traumatology, 17, 34-44.

Smart Richman, L., \& Leary, M. R. (2009). Reactions to Discrimination, Stigmatization, Ostracism, and Other Forms of Interpersonal Rejection: A Multimotive Model. Psychology Review, 116(2), 365-383. 
Spradley, J. (1979). Asking Descriptive Questions. The Ethnographic Interview. New York: Holt,

Rinehart \& Winston.

Stieglitz, K. A. (2004). Transgender youth's exploration of health care needs (Abstract). Paper presented at the conference program of the $17^{\text {th }}$ Annual Association of Nurses in AIDS Care (Conference, 100), New Orleans, L. A.

Stoller, R. J. (1979). Fathers of transsexual children. Journal of the American Psychoanalytic Association, 27, 837-866.

Taylor, B. J. (1994). Researching human health through interpretation. Armidale: The University of New England Press.

Tidefors, I., \& Olin, E. (2011). A need for "good eyes": Experiences told by patients diagnosed with psychosis. International Journal of Qualitative Studies in Health and Well-Being, $6(1)$

Trout, D. (1980). The Role of Social Isolation in Suicide. The Official Journal of the American Association of Suicidology, 10(1), 10-23.

Usher, R. (2006). North American Lexicon of Transgender Terms. San Francisco: GLB Publishers.

Vaughan, D. (1986). Uncoupling: Turning Points in Intimate Relationships. Oxford University Press.

Weyers, S., Elaut, E., Sutter, P., Gerris, J., T'Sojen, G., Heylens, G., . . Verstraelen, H. (2009). Long-term Assessment of the Physical, Mental, and Sexual Health among Transsexual Women. The Journal of Sexual Medicine, 6(3), 752-760.

Wilchins, R. A. (2002). Queerer bodies. In J. Nestle, C. Howell, \& R. A. Wilchins (Eds.), Genderqueer: Voices from beyond the sexual binary. Los Angeles: Alyson.

Wilging, C. E., Salvador, M., \& Kano, M. (2006). Unequal treatment: Mental health care for 
sexual and gender minority groups in a rural state. Psychiatric Sevices, 57, 867-870.

Willig, C. (2001). Introducing qualitative research in psychology Adventures in theory and method. Philadelphia: Open University Press.

Wong, C. F., Schrager, S. M., Holloway, I. W., Meyer, I. H., \& Kipke, M. D. (2014). Minority Stress Experiences and Psychological Well-Being: The Impact of Support from and Connection to Social Networks within the Los Angeles House and Ball Communities. Prevention Science, 15(1), 44-55.

Wylie, K., \& Wylie, R. (2016). Supporting trans people in clinical practice. Trends in Urology \& Men's Health.

Yarhouse, M. A., \& Carr, T. L. (2012). MTF transgender experiences: A qualitative study. Journal of LGBT Issues in Counselling, 6, 18-33.

Yunger, J. L., Carver, P. R., \& Perry, D. G. (2004). Does Gender Identity Influence Children's Psychological Well-Being? Developmental Psychology, 40(4), 572-58 